\title{
A.O. Карпов
}

\section{Становление теории образования для общества знаний и его реальности}

Аннотация. Общество знаний является одной из доминирующих парадигм современного соииальноэкономического развития, начало формирований которой приходится на вторую половину ХХ в. Этот процесс начёл своё особое выражение в культуре, социальной структуре, экономических инструментах и в образовании. Цель статьи - определение содержания теоретических представлений об образовании в обществе знаний в контексте зарождения его соииальной реальности.

Методология исследования выстроена в русле культурно-исторической эпистемологии; она базируется на анализе социально-экономического отночения кзнанию и познанию, в том числе учебному, использует компаративный анализ источников и сопоставление теоретических пропозиций с реальностью.

Показано, что генезис кониепиии образования в обществе знаний имеет своим началом период 1950-х - 1960-х гг. и обусловлен возникновением новых качеств индустриального работника, которые наследует работник знаний. В этот период П. Друкером формулируется идея опережающего обучения (1957) и приниип непрерывного образования для подготовки работника знаний (1968). Выявлена их связь с концепиией распределённого образования П. Друкера, которая, по его мнению, должна быть реализована после того, как непрерывное образование станет нормой. Установлено, что ключевыми институтами развития общества знаний являются университет и школа, построенные на принципах исследовательского обучения и связанные научно-познавательной преемственностью. Определено понятие динамической компетентности и показана связь идеи творческого обучения с теорией общества знаний и его реальностью. Дан анализ фундаментальных противоречий, сопровождающих развитие образования в обществе знаний.

Ключевые слова: образование, общество знаний, опережающее обучение, непрерывное образование, динамическая компетентность, творчество, наука, инновации, работник знаний, университет.

Abstract. Knowledge-based society is one of the dominating paradigms of a modern socio-economic development which was formed at the second half of the XXth century. The process was reflected in culture, social structure, economic tools and education. The purpose of the present article is to define contents of the theoretical concept of education in a knowledge-based society in terms of origin of its social reality. The research methodology involves cultural-historical epistemology that is based on the analysis of socio-economic attitudes to knowledge and cognition including academic learning as well as comparative analysis of references and comparison of theoretical propositions to reality. It is well shown that development of the knowledge-based education concept started in the 1950s - 1960s and was conditioned by the appearance of new qualities of an industrial worker that are then inherited by an knowledge worker. It was the period when Peter Drucker proposed the idea of proactive training (1957) as well as the principle of continuous education of a knowledge worker (1968). The author of the present article describes how aforesaid ideas relate to the concept of distributed education offered by Drucker which was supposed to be implemented after continuous education becomes a norm. The author also states that the key institutions for the development of the knowledge-based society include universities and schools built on the principals of research education and academic continuity. The author gives a definition of dynamic competence and describes the relationship between the idea of creative education and the theory of knowledge-based society. The author also provides an analysis of fundamental contradictions that accompany education development in a knowledge-based society.

Keywords: university, knowledge worker, innovations, science, creativity, dynamic competence, continuous education, proactive education, knowledge-based society, education. 


\section{Введение}

$\mathrm{B}$ середине XX в. в социально-экономической реальности индустриально развитых стран мира было намечено движение в направлении общества знаний. Этот процесс нашёл своё особое выражение в культуре, социальной структуре, экономических инструментах и, конечно же, в образовании. В социально-гуманитарном нарративе последних десятилетий высказывались предположения о парадигмальном характере происходящих перемен, иначе говоря, о фундаментальных трансформациях метода, содержания среды и институциональных основ обучения.

Так, У.Е. Долл говорит о создании новой концепции познания в образовании, которая должна быть ориен тирована на создание знания, а на его обсуждение и верификацию [1, p. 157, 109, 216]. В.В. Краевский считает одной из важных задач современный педагогической науки разработку нового содержания образования и соответствующих ему методов [2, с. 16]. П. Бурдьё предлагает идею исследовательской педагогики, в основу которой он кладёт создание габитусов изобретательства, творчества, свободы [3, с. 8-31]. Л.А. Микешина пишет, что «радикальные изменения в сфере обучения и образования в целом, формирующие новый интеллект, - это в значительной мере программа, разрабатывающая приёмы и операции преобразования коренной интуиции» $[4$, с. 246]. Педагогическая концепция К.-Г. Флейхзига опирается на множественность стилей преподавания и ученических стратегий, которые создают многообразные условия для содержания образования [5, S. 351-360]. Обучение через контексты, которое предлагает Р. Гоудон, опирается на реалии социального мира и межсубъектный характер познания как фактор когнитивного разнообразия [6, p. 593, 594, 599]. Д. Карр указывает на возросшие возможности общества привлечь к задачам обучения институции, специализированные относительно функций, которые выполняет знание в постиндустриальной культуре [7, р. 9, 16, 14]. К. Уинч рассматривает образование с точки зрения требований современного профессионального труда, для которого важна способность критически оценивать и отвечать на новые ситуации [8, p. 476, 477].

Сегодня школы как никогда являются значимой частью проблемы образования в университетах, поскольку учебная эффективность последних напрямую зависит от степени когнитивной готовности ученика к овладению сложными системами профессионально-специализированных знаний. Специалисты говорят о заметном несоответствии между развитием и интеллектуальными потребностями обучающихся, с одной стороны, и образовательной средой в школах и высших учебных заведениях, с другой $[9$, p. 10, 9]. Так, по данным одного из крупнейших исследований, проведённого в 26 штатах США, почти 40\% опрошенных считают, что материал, которому обучают в школе, не актуален для жизни, 45\% не чувствуют себя важной частью школьных сообществ и только $2 \%$ сказали, что им никогда не было скучно в школе [10, p. 1, 5]. Пассивность обучающихся вызывает модель образовательного учреждения как транслятора инструкций, преодоление которой является одной из основных задач образовательной теории и практики во всем мире [9, р. 3].

На современном этапе развития общества, как показал европейский социологический анализ, существует высокий уровень совпадений компетенций «для трудоустройства»с теми, которые участвуют в проведении исследовательской деятельности [11, p. 16, 29, 40, 47]. Такое совпадение свидетельствует о формировании в процессе становления общества знаний социализации научно-исследовательского типа. Она предполагает формирование сложных компетенций высокого уровня, которое требует длительного времени, а, следовательно, должно начинаться на этапе школьного образования. Отсюда, одним из главных вызовов образования становится необходимость обеспечения научнопознавательной преемственности между школой и университетом, для которой требуется особая, генеративная учебная среда и научно-исследовательские методы познания [12, p. 531-534].

Целью статьи является определение содержания теоретических представлений об образовании в обществе знаний в контексте зарождения его социальной реальности. Я полагаю, что 


\section{Педагогика и просвещение 3(23) • 2016}

образовательная теория должна исходить из фундаментальных культурных и социальных оснований своего времени. Только так она может стать действенной теорией, обрести научный статус и дать продуктивные импликации для социальной практики.

Методология исследования выстроена в русле культурно-исторической эпистемологии; она базируется на анализе социально-экономического отношения к знанию и познанию, в том числе учебному, использует компаративный анализ источников и сопоставление теоретических пропозиций с реальностью.

Результаты, опубликованные в статье, получены при выполнении проектной части государственного задания Министерства образования и науки Российской Федерации (грант №27.1560.2014/К).

\section{Работа со знанием и работник знаний в новой системе разделения труда}

В 1940-х-1950-х гг. работа со знанием становится новым элементом в системе разделения труда, которую она начинает преобразовывать [13, с. 814-817].

В 1962 г. Ф. Махлуп публикует пионерский труд «Производство и распространение знаний в США», главная задача которого есть «развитие концептуальной основы для анализа производства знаний» [14, p. 10]. Проведённый им статистический анализ показал, что американская индустрия знаний в середине XX в. производит почти $29 \%$ валового национального продукта (ВНП), а доля рабочей силы с учетом ее потенциальной, студенческой, части составляет 42,8\%. «Никто не ожидал, - писал позднее Махлуп, - что производство знаний в США имеет порядок величины, рассчитанной мной для 1958 года» [15, p. xxvixxviii]. В 1967 г., по оценке М. Пората, на сектор производства знаний и информации и на нерыночные услуги в этой области приходилось уже 46,2\% ВНП [16, р. 71]. К 1970 г. число людей, работающих со знанием, в «потенциальной рабочей силе» по расчётам Ф. Махлупа и Т. Кронвинклера (1975), увеличилось до 53,1\% [17, p. 757, 759].

Работа со знанием оказывается необходимым дополнением, а затем пронизывает все су- щество труда рабочего-станочника, бизнесмена, управленца, техника, политика, транспортника, финансиста и неузнаваемо меняет её. Отсюда формируется новая культурная сущность труда, которая есть участие работы с научным знанием в его социально значимых видах; т.е. то, что я называю «научная гибридизация труда». Имеется в виду как труд физический, ручной, так и умственный, как труд промышленный, так и организационный.

Когда я говорю, что профессиональный труд стал включать работу с научным знанием, имеется в виду не то, что научные знания вошли в обучение для этого труда и, тем самым, в квалификацию и действия работника. Имеется в виду непосредственное оперирование с научными знаниями как неотъемлемая часть новой работы, в том числе работы физической. Такая работа получила название «знаниевая работа» (knowledge work) или «знаниевый труд» (knowledge job). Еe появление фиксируется П. Друкером в 1957 г. [18, p. $69,122,121]$; хотя ещё в начале 1940 -х даже топменеджеры в крупных американских компаниях редко имели высшее образование, а IBM наняла своего первого менеджера с высшим образованием за год или два до начала Второй мировой войны [19, p. xviii, xvii].

Научные знания в новой работе «кодифицируются» в традиционных и превращенных формах: в научной периодике, технологиях, конструкциях, технике, чертежах, таблицах, схемах, регламентах и профессиональном слэнге.

Новый работник обладает гибридной природой: работа со знанием включает в его социальную группу «белые» и «синие» воротнички, но также в некотором смысле и «бело-синие». В социальной сфере научная гибридизация труда проникает в управление, охрану порядка, медицину, коммунальные службы, торговлю, церковь, масс-медиа, социальное обеспечение, etc. В технической сфере она создаёт особого рода гибриды - человеко-машинные системы. Они возникли как часть промышленности, гидроузлов, электрических сетей, логистики, инфраструктуры и технического сервиса в авиации, наземном и водном транспорте; чуть позже они воплотились в космические корабли и орбитальные станции. 
В гибридных технических системах человек представлен своим мышлением, но также способен задействовать труд своих рук. Последний - скорее эпифеномен его функциональной сущности как нового работника, которая есть работа со знанием. Однако когда работа со знанием соединяется в одном лице с работой технической (той, что отчасти заменила физический труд, но не изжила его), оно - это соединение - становится лицом новой профессиональной позиции «работник знаний» и новой системы разделения труда. В автоматизированных цехах несколько операторов заменили многие сотни рабочих. Основой для труда стало оперирование с моделями знаний, но их труд включал и ручные операции.

Развитие гибридных технических систем было вызвано в 1930-1940-х гг. подготовкой к войне и самой войной. Друкер пишет, что именно с периода Второй мировой войны «фактически начался переход (сдвиг, shift) к работе знаний и индустрии знаний», затронувший такие области деятельности, как обработку металлов, судостроение, строительство, управление, медицину, etc. [20, p. 252]; при этом отмечается «огромное (tremendous) смещение центра тяжести в рабочей силе от физического к знаниевому труду» [21, p. 160].

Событием, которое произвело решающий сдвиг в появлении работника знаний в Америке, полагает Друкер, стал «солдатский билль о правах» (G.I. Bill of Rights) - законодательный акт, подписанный президентом Ф. Рузвельтом 22 июня 1944 г. [22, p. хіi]. Закон предусматривал ряд льгот для возвращающихся с войны ветеранов; в их числе: денежные выплаты на обучение в университетах, школах, технических училищах (включая проживание) и низкопроцентные займы для того, чтобы начать бизнес. Другим, не менее знаковым событием, стало возникновение в 1946 г. в Америке венчурных фирм, которые создали новую экономическую реальность для человека знаний. В начальный период они рассматривали свою деятельность как инструмент финансирования «благородных идей» человека знаний и инвестировали в стартап-компании, которыми руководили солдаты, возвращающиеся с войны.

Термин «работник знаний» (knowledge worker) вводится П. Друкером в эпилоге книги «Новое общество» (1950), написанном в 1962 г. [22, р. 355, 356]. Однако, его появление как нового работника заметно значительно раньше. Работник, обладающий новыми знаниями, говорит Друкер в 1950 г., - это уже массовая часть нового среднего класса, это «нонмануальный (nonmanual) работник, интеллектуально и технически подготовленный человек, который является наиболее продуктивным членом общества». В стекольной промышленности, например, в конце сороковых годов ручной труд был почти полностью устранён, также как в нефтяной химии или производстве пластмасс.

В книге «Эпоха разрыва» (1968) Друкер определяет новое общество как общество знаний (knowledge society). Новая эпоха - это эра инноваций и технологических изменений, говорит Друкер. Новые отрасли являются знаниевым производством, а знание есть главный фактор их производительности [20, р. $54,10,154]$. Они используют работников знаний и производят товары и услуги с высоким содержанием знаний. Работник знаний создал современное сельскохозяйственное производство, которое стало наукоемкой отраслью (science industry). Оттуда он вытеснил рабочую силу в промышленность, сферу услуг, информационный и знаниевый сектора экономики [20, p. 67, 37, 15, 254, 11].

Друкер отличает работника знаний от работника умственного труда. Например, он использует термин «mind work», когда говорит об умственной работе, а не «knowledge work», характеризующий труд работника знаний. Работники знаний - это инженеры, компьютерные эксперты, учителя, медицинские техники, высококвалифицированные сельскохозяйственные рабочие, авиационные техники, etc. Таким образом работник знаний, по Друкеру, - отнюдь не работник умственного труда. Ведь «знание не устраняет ни работы, ни навыка» [20, р. 24, 236, 251-255].

Я полагаю, что работник знаний определяется прежде всего доминирующим типом труда, а не профессиональной принадлежностью. Основная функциональная составляющая труда работника знаний - это работа со знанием, способная задействовать продуктивное мышление. Вместе с тем в содержание труда работника знаний может входить труд физический. Когнитивно- 


\section{Педагогика и просвещение 3(23) • 2016}

механическая работа, т.е. работа, выполняемая посредством воспроизведения в мышлении ряда фиксированных ситуационных матриц, не принадлежит сфере деятельности работника знаний. Такую работу выполняют в торговых комплексах, охранной и пропускной службах, чиновничьих конторах, на транспортных узлах (например, вокзальные регистрационные сервисы и службы объявлений, etc.). Работник знаний может производить как материальную, так и нематериальную продукцию, но основой её производства является работа со знаниями. Таким образом, работник знаний не есть работник умственного или физического труда, а работник умственного труда далеко не всегда является работником знаний.

В 1967 г. Друкер пишет, что образование есть исключительный по значимости источник, который может дать конкурентные преимущества обществу и экономике; именно образование способно сделать работника знаний продуктивным. «Работник знания... становится главной инвестицией; а для образования - самой дорогой инвестицией из всех» $[21$, р. $5,171,172]$. В конце 1960-х гг., когда шла война во Вьетнаме, расходы на образование в США превышали затраты на оборону; за предшествующее десятилетие они выросли в два раза [20, р. 291].

\section{Генезис концепции образования для общества знаний}

Концепция образования для общества знаний начинает складываться во второй половине XX в. В этот период происходит изменение всей образовательной системы общества. C возникновением глобальной экономики и стремительным ускорением технологической революции высшее образование начинает терять свой элитарный статус, оно становится массовым и непосредственно ответственным за развитие общества. В 1940 г. в американских колледжах и университетахучилось около 15\% молодёжи в возрасте от 18 до 21 года; к 1963 г. их число выросло до 40\% [23, с. 175]. В Европе массовое высшее профессиональное образование формируется на 20 лет позже. В 60-х гг. европейские университеты охватывают всего 4-5\% соответствующей возрастной группы, сегодня - 40$50 \%$ [24]; в России эта цифра достигает 60\%.

В книге «Ориентиры будущего» (1957) П. Друкер выделяет главные части социальной структуры, из которых формируется новое общество. Это - инновационная система, включающая науку, особая система образования и бизнес-предприятие как модель новой социальной организации. Новый работник должен быть готов к работе в условиях интеграции социальных и технологических инноваций и в тех организациях, которые осуществляют эту функцию. Такие компетенции закладываются образованием [18, р. 19, 41, 42]. Отсюда, рядом с системой взглядов на инновационный характер нового общества следует выстраивание концепции «образованное общество» (educated society), т.е. общество, в основу существования которого положено образование.

Выход книги совпал с событием, принципиально изменившим отношение к системе образования в США и западном мире, причем в русле концепции, разработанной Друкером. 4 октября 1957 г. на орбиту Земли был выведен первый искусственный спутник - советский космический аппарат ПС-1 (Простейший Спутник-1). Значение этого события для формирования новой социальной группы работников знаний было отнюдь не простейшим, но эпохальным. В этот день президент США Д. Эйзенхауэр в обращении к американскому народу сказал: «Наши школы сейчас важнее наших радиолокационных станций; школы таят в себе большую силу, чем энергия атома». Будучи тогда еще конгрессменом, Дж. Кеннеди предупреждает американцев: «Не будет преувеличением сказать, что битва, которую мы ведем сейчас, может быть выиграна или проиграна в школьных классах Америки» [25, с. 217-218].

Проведенные в США исследования, которые обеспечивались щедрыми государственными ассигнованиями, показали, что особо критичным звеном системы образования является средняя школа, поскольку в ней «закладываются основы для научно-технической карьеры учащихся» [23, c. 176-177]. В ответ на политические и научнотехнические вызовы в США и Западной Европе начинает активно развиваться система научноисследовательской подготовки школьников, в 
которой участвуют многие действующие ученые и научные институты [26, с. 92, 93]. В России такая работа стала реальностью лишь с середины 1990-х гг., благодаря программе «Шаг в будущее» [27, с. 726-729]. Именно из этой реальности вырастает современный работник знаний.

Инновационная направленность общества накладывает особую печать на образование. В 1957 г. Друкер формулирует идею опережающего обучения и вплотную подходит к идее непрерывного образования для людей, занятых продуктивной работой со знанием. «Поскольку мы живем в эпоху инноваций, - пишет он, - практическое образование должно подготовить человека к такой работе, которая ещё не существует и которая не может быть чётко определена». Более эффективной с точки зрения подготовки нового работникаявляется образование, которое выстраивается не в хронологической последовательности, но в распределённой по времени конфигурации (назовём такое образование распределённым). Концепция распределённого образования Друкера предполагает, что структура образования должна позволять приобретать знание на тех этапах жизни человека, когда он эффективно с познавательной точки зрения может его воспринять. Эту познавательную эффективность определяет опыт и развитие мышления. Речь идёт об образовании взрослых (edult education), образовании как непрерывном процессе (education as a continuing process), которое «использует эти годы <обучения> наиболее эффективно и наиболее практично (economically)». Ведь знания - «это единственный реальный капитал сегодня», а «продуктивная работа в современном обществе... основана на уме, а не на руке» [18, р. 129, 147-149, 120].

В 1962 г. в работе «Производство и распространение знаний в США»Ф. Махлуп пишет, что образование (среднее и высшее) является крупнейшей областью индустрии знаний (ей посвящена самая большая часть книги). «Уровень ресурсного обеспечения образования, научных исследований и разработок представляет собой важную экономическую переменную, которая способна существенно изменить темпы роста знания, причём и фундаментального, и прикладного». Вот почему наблюдается «такой всплеск активности в изучении продуктивности инвестиций в знания» $[14$, p. 11,5$]$.

В «Эпохе разрыва» (1968) Друкерутверждает необходимость нового подхода к образованию, которое должно быть способно обучать работника знаний. Новое образование должно формировать «универсальное умение, которое состоит в использовании знаний и их систематическом приобретении как основы для эффективности, квалификации и достижений». Он говорит о «всеобщем» обучении технологов в смысле техники применения знаний. Здесь же Друкер связывает идею непрерывного образования (continuing education) с высокой динамикой изменения знаний, которые используются в работе. Необходимость постоянной переподготовки касается всех работников знаний - инженеров, врачей, математиков, учителей, etc. Когда непрерывное образование станет нормой, следует реализовывать идею распределенного образования, полагает Друкер. Вместо увеличения срока первоначального обучения, надо будет разбить его на части и распределить обучение на всю активную жизнь. Поэтому самое главное в образовании для общества знаний научить человека как учиться [20, p. 299, 300-303].

В докладе ЮНЕСКО «К обществам знания» (2005) концепция обучения в течение жизни (lifelong learning) связывается с понятием «обучающееся общество» (learning society), введение которого авторы доклада относят к работам Р. Хатчинса (1968) и Т. Хусена (1974) [28, р. 57]. Между тем в книге П. Друкера «Ориентиры будущего» (1957), как я показал, описание «общества, в основу которого положено образование» (educated society) содержит чётко сформулированные представления об опережающем обучении и образовании как непрерывном в течение жизни процессе. Такое образование определяется в качестве ключевого инструмента концепции инновационного развития.

Говоря о новизне взглядов Друкера, следует отметить, что для периода 1950-х-1960-х гг. более характерны романтические представления о роли образования для взрослых (education for adults), которые наследуют общественное сознание XIX в. и говорят о «гуманизации» или «переработке» (refining) в основном бедных лю- 


\section{Педагогика и просвещение 3(23) • 2016}

дей, об образовании рабочих. В их основе лежало побуждение сделать обучение непосредственной частью процесса социальных изменений. А. Сток замечает, что эти «высокие романтические предположения... часто не согласуются с реальным миром обыкновенных трудящихся» [29, p. 10-13].

Новая образовательная система, по Друкеру, должна обеспечивать воспитание талантов для экономики знаний, подготовку работника знаний к той работе, которая ещё не существует (опережающее обучение), его переподготовку в течение всей жизни (непрерывное образование) и, как следствие, мобильность новой рабочей силы [20, p. 114, 300, 306, 286].

В «Эпохе разрыва» Друкер утверждает, что из всех организаций базовую роль в развитии общества знаний и его работника будет играть университет, - университетские лаборатории являются основой научного производства, из которых оно вырастает [20, p. 187, 167]. Тогда же М. Троу говорит, что в современных обществах поиски нового знания и новых способов его применения превратились в важную сферу деятельности, а колледжи и университеты призваны решать эту задачу, которая приобретает все большее значение [23, с. 186, 187].

Через 12 лет после выхода книги Друкера в Соединённых Штатах был принят акт БэяДоуэла (Bayh-Dole Act-1980), снявший препоны на трансфер научных знаний и технологий из университетов в корпоративный сектор. В течение нескольких лет университеты создали более двух тысяч компаний (260 тыс. рабочих мест), которые занимались коммерциализацией технологий. До принятия акта все американские университеты регистрировали менее 250 патентов в год; в 1992 г. их стало 1500, а в 2010 г. - 4500, т.е. за 30 лет рост составил $1700 \%$. Значительный объем лицензий, которые они получают за эти патенты, делает их постепенно коммерческими организациями. Если в период 1989-1990 гг. университеты получили 82 млн. долл. лицензионного дохода, то в 2009 г. - более 1,5 млрд. долл. $[30$, c. 167,168$]$. Так, доход Кембриджского университета от интеллектуальной деятельности достигает 3,5 млн. евро в год. Только в 2008 г. было получено 120 патентов и 35 лицензий.
Университеты и промышленность всё более тесно взаимодействуют там, где открытия переводятся в инновационные продукты и коммерциализируются при помощи подходящих бизнесмоделей [31, с. 36, 311, 297]. Дж. Коул считает, что «значительная часть ведущих отраслей промышленности в США, возможно более 80 процентов, произошло из открытий в американскихуниверситетах» [32, p. 4]. В 1999 г. Д. Белл указывает в качестве источников технологического лидерства США сильные наукоёмкие исследовательские университеты, сильную предпринимательскую культуру и венчурный капитал для финансирования малого бизнеса [33, p. xl, xliii]. В начале 2000 -х гг. в Европе основная роль в создании общества знаний отводится университетам, поскольку они находятся на пересечении научных исследований, образования и инноваций [34, p. 1]. На европейском совещании в Хэмптон-Корте университеты, наряду с исследованиями и разработками были названы основой европейской конкурентоспособности [35, p. 2].

Однако, по мнению Друкера, в ближайшем будущем вряд ли можно рассчитывать на то, что удастся измерить «выход» знаниевой работы; её «нелегко определить в количественном отношении, а может быть это сделать вообще невозможно». Так, эффективность работы университета пытаются определить по таким параметрам, как «зарплата выпускников и их должности», «репутация», «количество учёных степеней и премий», «объём средств, привлечённых на развитие». Друкер полагает, что оценка работы университета по критериям эффективности также же сомнительна, как подсчёт больничных коек для определения эффективности психиатрических больниц [20, p. 269, 270, 183]. Это заключение всемирно признанного специалиста в области менеджмента весьма поучительно для реальности российского образования.

Друкер определяет новую способность, которую должен иметь работник в обществе знаний: ему «придётся научиться понимать динамику технологии и предвидеть направление и скорость технологических изменений» [20, p. 40]. Такую способность я определяю термином «динамическая компетентность» [36, с. 14-15]. Она опирается на чувство самостоятельного пред- 
видения направлений изменения в содержании и конфигурациях профессионального знания. Она определяется исследовательским складом ума, готового воспринимать и прогнозировать глубинные изменения парадигмального типа, проникать в принципиально незнаемое, т.е. такое незнаемое, которое обладает системной непредвиденностью как невозможностью получения просто логическим продолжением устоявшейся конфигурации знаний. Динамическая компетентность создается посредством исследовательского обучения, которое относится к знанию как к непредвиденному событию. Такое обучение, как я показал, составляет горизонт развития современного образования [37, р. 373-376].

Человеческое творчество определяется Друкером в качестве движущей силы экономического роста и развития нового общества [22, p. 161, 184]. Эта идея имеет непосредственное влияние на современное образование.

Так, в 2006 г. Ассоциация европейских университетов (EUA) инициирует исследовательский проект «Творчество в высшем образовании», который финансируется Европейской Комиссией в рамках программы «Socrates». Главная цель проекта - «внести вклад в продвижение европейского общества знаний». Доклад, выпущенный EUA по результатам исследования (2007), констатировал, что творчество, и в первую очередь творчество в университетах как центрах создания знаний, является ключевым фактором для решения сложных социально-экономических проблем и основной движущей силой развития общества знаний. С творчеством тесно связано латеральное мышление, которое требуется для того, чтобы принять во внимание все известные факторы [38, p. 6, 10, 20].

В 2008 г. доклад ООН «Креативная экономика» говорит о возникновении новой парадигмы развития, «которая связывает экономику и культуру, охватывая экономические, культурные, технологические и социальные аспекты развития как на микро-, так и на макроуровне». Экономический аспект творчества способствует предпринимательству, инновациям, экономическому росту. Он относится к созданию культурной продукции, научным изобретениям, технологическим новшествам. Концепция «креативная экономика»свидетельствует о переходе от традиционных моделей развития к междисциплинарной [39, p. 3-4]. Образование находится в центре связи экономики и творчества, а «глобальные культуры распространяются в виде знаний и научно-исследовательских сетей» [40, p. 1]. Вместе с тем, Л. Хаммершоу отмечает, что «исследования креативности в контексте обсуждения экономики общества знаний начались относительно недавно. ... и в особенности здесь не хватает исследований в сфере теоретического понимания творчества в образовании» $[41$, p. 546].

\section{Противоречия образования в реальности общества знаний}

В качестве фундаментальных противоречий, сопровождающих развитие образования в реальности общества знаний, я определяю следующие: (1) противоречие, связанное с коммодификацией (товаризацией) знания; (2) противоречие между работником знаний и менеджером; (3) противоречие между знанием и информацией; (4) противоречие между научным знанием и не научным.

Главное из этих противоречий порождается коммодификационной политикой, которая включает образование и науку в систему товарных отношений. Товаризация знания формирует коммерческую среду, враждебную творческой мысли, это знание создающей. В результате чего, как мною было показано, из процесса обучения исключаются созидательные свойства личности и социокультурные связи знания, творческая функция обучающего и обучаемого, связь обучения с исследованиями и мотивация к ним, а также воспитательная функция исследования, которая формирует научную методичность мышления и определяет высокое качество образования [42, с. 85-96].

Одно из самых острых противоречий общества знаний - это противоречие между работником знаний (преподавателем, учителем, учёным, высококвалифицированным специалистом) и чистым менеджером, который далеко не всегда может быть отнесён к группе работников знаний. Но даже когда он выполняет функцию работника знаний, он не свободен от этого противоречия. 


\section{Педагогика и просвещение 3(23) • 2016}

В «Эпохе разрыва» менеджеризм Друкера достигает аподиктических высот. «Босс» работника знаний, пишет Друкер, - это «менеджер, как правило не сведущий в его дисциплинарной области, но обладающий специальными компетенциями в области планирования, организации, интеграции коллектива и оценки работы людей знания (knowledge people) независимо от их дисциплины или области специализации». Так, для управления университетом нужны прежде всего менеджеры [20, p. 251, 332]. В «Посткапиталистическом обществе» (1993) он скажет - в организации, основанной на знаниях, руководители не должны знать работу своих подчинённых [43, p. 107].

Сегодня менеджеризм позиционируется как идеология, утверждающая превосходство чистого управления и руководства - его абстрактных обоснований и схем - над любой другой формой и способом организации социальных институтов и деятельности. Менеджеризм постулирует, что его социотехнические практики универсальны и всегда лучше контекстно-профессионального подхода в управлении коллективами людей в современном обществе [44, p. 6]. Наши дни показали разрушительные последствия, которые возникают при попытке «неакадемических» людей наложить чисто организационное видение на академическую культуру, которая лежит в основе научного образования и научного производства знаний. Школой могут руководить люди, не знающие педагогику, больницей - не знающие анатомию, университетом и научным институтом - чиновники или выходцы из бизнеса, т.е. те, кто являются «эффективными менеджерами», кто лишь «ответственен за применение и эффективность (performance) знания» [43, p. 44]; люди, не сведущие в научном знании; люди, идущие по мелководью.

Противоречие между знанием и информацией не менее значимо. Это - противоречие между внутренним (осмысленным) и внешним (поверхностным) пониманием, между самостоятельным и социально программируемым мышлением. При анализе процессов обучения Друкер определяет в качестве информации арифметику, историю, язык, музыкальную грамоту [20, p. 319-320]. Порат также относит учителей к информационным работникам (категория «распространители знания»), ставя их в один ряд с канцелярскими работниками, бухгалтерами и телефонными операторами [16, p. 71, 73].

Сегодня мы видим, как смешение понятий «информация» и «знание»делает легитимными изменения в жизни людей, экономике и социальной структуре по воле чиновника или на основе ангажированного экспертного мнения, а не научного исследования проблемной ситуации [45, с. 34-36]. В образовании знание, определяемое как информация, обретает статус временного приобретения, которое отнюдь не является необходимым для жизни и работы. Такое «знание» элиминирует возможность не только работника знаний, но и общества знаний как такового.

Социально критичным становится противоречие между научным знанием и ненаучным. Оно обостряется тогда, когда второе подменяет первое. В случае если исследование, конструирование, проектирование нацелено только на эффективность конечного результата, оно отнюдь не заинтересовано в изучении тех факторов, которые не влияют на эффективность. Таким образом создаются вещи и технологии, непредсказуемые по их последствиям. Обоснованием их существования оказываются паллиативная теория, рецептурные предписания и ограниченный набор эмпирических данных, которые определяются заказчиком, а не научной необходимостью [46, с. 201-203].

Знание способно терять статус научного, когда оно утверждается как конъюнктурное знание, т.е. знание, устремлённое прежде всего к внешнему стимулу, а не к истине. Для процессов производства знаний решающим становится контекст использования, а не контекст открытия и обоснования в научном обществе [47, p. 12]. Неконтролируемая коммерциализация науки вызывает размывание фундаментальной специализации университетов и её структурный дисбаланс на национальном уровне, поскольку способствует гипертрофированному развитию тех направлений исследований, которые сулят быстрое вознаграждение [30, с. 178-179]. 


\section{Выводы}

Общество знаний как особое социальное пространство современного общества формируется в 1940-х-1960-х гг. Его центрами кристаллизации являются новая система разделения труда, инновационные институты развития, образовательные организации, воспитывающие работника знаний. Социальный заказ на подготовку работника знаний, способного быть продуктивным в условиях динамично меняющегося знания и технико-технологического окружения, является одним из главных вызовов современного образования.

Представления о системе образования, которая способна дать ответ на этот вызов, формируются в 1950-х-1960-х гг. Как показывает П. Друкер, такая система образования базируется на идее опережающего обучения (1957) и принципе непрерывного образования для работника знаний (1968). Концепция распределённого образования, созданная в этот период Друкером, по его мнению, должна быть реализована после того, как непрерывное образование, станет нормой.

Университет и школа, построенные на принципах исследовательского обучения и связанные научно-познавательной преемственностью, являются ключевыми институтами развития общества знаний. Творческий характер обучения определяет способность работника знаний к социальным и технико-технологическим инновациям, а исследования формируют его динамическую компетентность и социальноэкономическую продуктивность.

\section{Список литературы:}

1. Doll W.E. A Post-modern Perspective on Curriculum. New York and London: Teacher College Press, Columbia University, 1993. 215 p.

2. Краевский В.В., Бережнова Е.В. Основы учебно-исследовательской деятельности студентов. М.: Изд. центр «Академия», 2005. 128 с.

3. Бурдье П. Университетская докса и творчество: против схоластических делений / Пер. с франц. H.А. Шматко. M.: Socio-Logos, 1996. C. 8-31. URL: http// bourdieu.name/content/burde-universitetskaja-doksa-i-tvorchestvo-protiv-scholastiches-kich-delenij (дата обращения: 06.05.2012).

4. Микешина Л.А. Философия познания. Полемические главы. М.: Прогресс-Традиция, 2002. 624 с.

5. Flechzig K.-H. Vielfalt und Transversal Vernunft. Prinzipien postmodernen Denkens und die Modernisierungskrise in Bildungssystemen // Zeitschrift für Pädagogik. Weinheim; Basel: Beltz, 1992. Beiheft 29. S. 351-360.

6. Godon R. Understanding, Personal Identuty and Education // Journal of Philosophy of Education. Oxford: Blackwell Publishing, 2004. Vol. 38. No 4. P. 589-600.

7. Carr D. Making Sense of Education. London and New York: Routledge Falmer, 2003. 294 p.

8. Winch C. Developing Critical Rationality as a Pedagogical Aim // Journal of Philosophy Education. Oxford: Blackwell Publishing, 2004. Vol. 38. No 3. P. 467-484.

9. Shernoff D.J. Optimal Learning Environments to Promote Student Engagement. New York: Springer Science+Business Media, 2013. 380 p.

10. Yazzie-Mintz E. Voices of Students on Engagement: A Report on the 2006 High School Survey of Student Engagement. Bloomington: Center for Evaluation \& Education Policy, Indiana University, 2007.12 p.

11. Developing Foresight for the Development of Higher Education/Research Relations in the Perspective of the European Research Area (ERA) / by Prof. Etienna Bourgeois // Final Report of the Strata-Etan Expert Group. Brussels: European Commission, Directorate-General for Research. Unit RTD-K.2. 2002. 82 p.

12. Karpov A.O. Integrated and network systems of research education in the knowledge society (by example of the Russian educational system) // Mediterranean Journal of Social Sciences. Rome: MCSER Publishing, 2015. Vol. 6. No 6 (November). P. 529-540. 


\section{Педагогика и просвещение 3(23) • 2016}

13. Карпов А.О. Основные теоретические понятия общества знаний // Вестник Российской академии наук. 2015. №9. С. 812-820.

14. Machlup F. The Production and Distributation of Knowledge in the United States. Princeton: Princeton University Press, 1972. 416 p.

15. Machlup F. Knowledge: Its Creation, Distribution and Economic Significance. Vol. I: Knowledge and Knowledge Production. Princeton: Princeton University Press, 2014. 272 p.

16. Porat M.U. Global Implications of the Information Society // Journal of Communication. Hoboken (USA): John Wiley \& Sons, 1978. Vol. 28. Issue 1. P. 70-80.

17. Machlup F., Kronwinkler T. Workers Who Produce Knowledge: A Steady Increase, 1900 to 1970 // Review of World Economics. Berlin: Springer Berlin Heidelberg, 1975. Vol. 111. Issue 4. P. 752-759.

18. Drucker P.F. Landmarks of Tomorrow. A Report on the New «Post-Modern» World. NY.: Harper, 1996. $270 \mathrm{p}$.

19. Drucker P.F. Concept of the Corporation. Piscataway: Transaction Publishers, Rutgers - The State University of New Jersey, 2008. 362 p.

20. Drucker P.F. The Age of Discontinuity: Guidelines to our Changing Society. London: Heinemann, 1969. $369 \mathrm{p}$.

21. Drucker P.F. The Effective Executive. Oxford: Elsevier, 2007. 167 p.

22. Drucker P.F. The New Society. The Anatomy of Industrial Order. N.Y.: Harper, 2010. 362 p.

23. Троу М. Социология образования // Американская социология. Перспективы, проблемы, методы. М.: Прогресс, 1972. С. 174-187.

24. Anderson R. The «Idea of a University's today». URL: http://www.historyandpolicy.org/papers/policypaper-98.html (дата обращения: 16.10.2011).

25. Галаган А.И. Закон США «Об обеспечении улучшения федеральных исследований образования, образовательной статистики, оценки образования, информации об образовании и ее распространения и других целей» // Ежегодник российского образовательного законодательства. Т. 1. M., 2006. C. 217-274.

26. Карпов А.О. Образование для общества знаний: генезис и социальные вызовы // Общественные науки и современность. 2015. №5. С. 86-101.

27. Карпов А.О. Локус научной одаренности: программа «Шаг в будущее» // Вестник Российской академии наук. 2012. Т. 82. №8. С. 726-729.

28. Towards Knowledge Societies. UNESCO World Report. Paris: UNESCO Publishing, 2005. 226 p.

29. Stock A. Lifelong learning: thirty years of educational change // The Learning Society: Challenges and Trends / ed. by P. Raggat, R. Edwards and N. Small. Routledge: Abingdon; N.Y., 2013. 314 p.

30. Игнатов А.А. Роль Акта Бэя-Доуэла (Bayh-Dole Act-1980) в трансфере научных знаний и технологий из американскихуниверситетов в корпоративный сектор: итоги тридцатилетнего пути // Наука. Инновации. Образование. М.: Языки славянской культуры, 2012. Вып. 12. С. 159-188.

31. Чесбро Г. Открытые инновации / Пер. с англ. В.Н. Егорова. М.: Поколение, 2007. 336 с.

32. Cole J.R. The Great American University: Its Rise to Preeminence, Its Indispensable National Role, Why It Must be Protected. N.Y.: PublicAffairs, 2010.616 p.

33. Bell D. The Axial Age of Technology Foreword: 1999 // Bell D. The Coming of Post-Industrial Society: A Venture of Social Forecasting. N.Y.: Basic Books, 2008. P. ix-lxxxvi.

34. The Role of the Universities in the Europe of Knowledge / Communication from the Commission. Brussels: Commission of the European Communities, 2003. 23 p.

35. Delivering on the Modernisation Agenda for Universities: Education, Research and Innovation / Communication from the Commission to the Counsil and the European Parlament. Brussels: Commission of the European Communities, 2006.16 p.

36. Карпов А.О. Социокогнитивная структура и образование в обществе знаний // Общество и экономика. М., 2013. №11-12. С. 5-20. 
37. Karpov A.O. Knowledge Society: A Weak Link // Herald of the Russian Academy of Sciences. N.Y.: Pleiades Publishing, 2010. Vol. 80. №4. P. 373-376.

38. Creativity in Higher Education: Report on the EUA Creative Project - 2007. Brussels: European University Association, 2007. 44 p.

39. Creative Economy Report 2008. N.Y.: United Nations, 2008. 332 p.

40. Peters A., Besley T. Introduction: The Creative University // The Creative University / ed. by A. Peters, T. Besley. Rotterdam: Sense Publishers, 2013. 190 p.

41. Hammershoj L.G. Creativity as a Question of Bildung // Journal of Philosophy of Education. Oxford: Blackwell Publishing, 2009. Vol. 43. №4. P. 545-557.

42. Карпов А.О. Коммодификация образования в ракурсе его целей, онтологии и логики культурного движения // Вопросы философии. 2012. №10. С. 85-96.

43. Drucker P.F. Post-Capitalist Society. New York City: Harper Business, 1993. 232 p.

44. Deem R., Hillyard S., Reed M. Knowledge, Higher Education, and the New Managerialism: The Changing Management of UK Universities. N.Y.: Oxford University Press, 2010. P. 6.

45. Карпов А.О. Онтологизация, “онтологизация" и образование // Вопросы философии. 2013. №9. C. 34-36.

46. Пружинин Б.И. Ratio serviens? Контуры культурно-исторической эпистемологии. М.: РОССПЭН, 2009. $423 \mathrm{c}$.

47. Bechmann G., Gorokhov V., Stehr N. Introduction // The Social Integration of Science: Institutional and Epistemological Aspects of the Transformation of Knowledge in Modern Society. Berlin: Editional Sigma, 2009. $312 \mathrm{p}$.

\section{References (transliterated)}

1. Doll W.E. A Post-modern Perspective on Curriculum. New York and London: Teacher College Press, Columbia University, 1993. 215 p.

2. Kraevskii V.V., Berezhnova E.V. Osnovy uchebno-issledovatel'skoi deyatel'nosti studentov. M.: Izd. tsentr «Akademiya», 2005. $128 \mathrm{~s}$.

3. Burd'e P. Universitetskaya doksa i tvorchestvo: protiv skholasticheskikh delenii / Per. s frants. N.A. Shmatko. M.: Socio-Logos, 1996. S. 8-31. URL: http// bourdieu.name/content/burde-universitetskaja-doksa-i-tvorchestvo-protiv-scholastiches-kich-delenij (data obrashcheniya: 06.05.2012).

4. Mikeshina L.A. Filosofiya poznaniya. Polemicheskie glavy. M.: Progress-Traditsiya, 2002. 624 s.

5. Flechzig K.-H. Vielfalt und Transversal Vernunft. Prinzipien postmodernen Denkens und die Modernisierungskrise in Bildungssystemen // Zeitschrift für Pädagogik. Weinheim; Basel: Beltz, 1992. Beiheft 29. S. 351-360.

6. Godon R. Understanding, Personal Identuty and Education // Journal of Philosophy of Education. Oxford: Blackwell Publishing, 2004. Vol. 38. No 4. P. 589-600.

7. Carr D. Making Sense of Education. London and New York: Routledge Falmer, 2003. 294 p.

8. Winch C. Developing Critical Rationality as a Pedagogical Aim // Journal of Philosophy Education. Oxford: Blackwell Publishing, 2004. Vol. 38. No 3. P. 467-484.

9. Shernoff D.J. Optimal Learning Environments to Promote Student Engagement. New York: Springer Science+Business Media, 2013. 380 p.

10. Yazzie-Mintz E. Voices of Students on Engagement: A Report on the 2006 High School Survey of Student Engagement. Bloomington: Center for Evaluation \& Education Policy, Indiana University, 2007.12 p.

11. Developing Foresight for the Development of Higher Education/Research Relations in the Perspective of the European Research Area (ERA) / by Prof. Etienna Bourgeois // Final Report of the Strata-Etan Expert Group. Brussels: European Commission, Directorate-General for Research. Unit RTD-K.2. 2002. 82 p. 


\section{Педагогика и просвещение 3(23) • 2016}

12. Karpov A.O. Integrated and network systems of research education in the knowledge society (by example of the Russian educational system) // Mediterranean Journal of Social Sciences. Rome: MCSER Publishing, 2015. Vol. 6. No 6 (November). P. 529-540.

13. Karpov A.O. Osnovnye teoreticheskie ponyatiya obshchestva znanii // Vestnik Rossiiskoi akademii nauk. 2015. №9. S. 812-820.

14. Machlup F. The Production and Distributation of Knowledge in the United States. Princeton: Princeton University Press, 1972. 416 p.

15. Machlup F. Knowledge: Its Creation, Distribution and Economic Significance. Vol. I: Knowledge and Knowledge Production. Princeton: Princeton University Press, 2014. 272 p.

16. Porat M.U. Global Implications of the Information Society // Journal of Communication. Hoboken (USA): John Wiley \& Sons, 1978. Vol. 28. Issue 1. P. 70-80.

17. Machlup F., Kronwinkler T. Workers Who Produce Knowledge: A Steady Increase, 1900 to 1970 // Review of World Economics. Berlin: Springer Berlin Heidelberg, 1975. Vol. 111. Issue 4. P. 752-759.

18. Drucker P.F. Landmarks of Tomorrow. A Report on the New «Post-Modern» World. NY.: Harper, 1996. $270 \mathrm{p}$.

19. Drucker P.F. Concept of the Corporation. Piscataway: Transaction Publishers, Rutgers - The State University of New Jersey, 2008. 362 p.

20. Drucker P.F. The Age of Discontinuity: Guidelines to our Changing Society. London: Heinemann, 1969. $369 \mathrm{p}$.

21. Drucker P.F. The Effective Executive. Oxford: Elsevier, 2007. 167 p.

22. Drucker P.F. The New Society. The Anatomy of Industrial Order. N.Y.: Harper, 2010. 362 p.

23. Trou M. Sotsiologiya obrazovaniya // Amerikanskaya sotsiologiya. Perspektivy, problemy, metody. M.: Progress, 1972. S. 174-187.

24. Anderson R. The «Idea of a University's today». URL: http://www.historyandpolicy.org/papers/policypaper-98.html (data obrashcheniya: 16.10.2011).

25. Galagan A.I. Zakon SShA «Ob obespechenii uluchsheniya federal'nykh issledovanii obrazovaniya, obrazovatel'noi statistiki, otsenki obrazovaniya, informatsii ob obrazovanii i ee rasprostraneniya i drugikh tselei» // Ezhegodnik rossiiskogo obrazovatel'nogo zakonodatel'stva. T. 1. M., 2006. S. 217-274.

26. Karpov A.O. Obrazovanie dlya obshchestva znanii: genezis i sotsial'nye vyzovy // Obshchestvennye nauki i sovremennost'. 2015. №5. S. 86-101.

27. Karpov A.O. Lokus nauchnoi odarennosti: programma «Shag v budushchee» // Vestnik Rossiiskoi akademii nauk. 2012. T. 82. №8. S. 726-729.

28. Towards Knowledge Societies. UNESCO World Report. Paris: UNESCO Publishing, 2005. 226 p.

29. Stock A. Lifelong learning: thirty years of educational change // The Learning Society: Challenges and Trends / ed. by P. Raggat, R. Edwards and N. Small. Routledge: Abingdon; N.Y., 2013. 314 p.

30. Ignatov A.A. Rol' Akta Beya-Douela (Bayh-Dole Act-1980) v transfere nauchnykh znanii i tekhnologii iz amerikanskikh universitetov v korporativnyi sektor: itogi tridtsatiletnego puti // Nauka. Innovatsii. Obrazovanie. M.: Yazyki slavyanskoi kul'tury, 2012. Vyp. 12. S. 159-188.

31. Chesbro G. Otkrytye innovatsii / Per. s angl. V.N. Egorova. M.: Pokolenie, 2007. 336 s.

32. Cole J.R. The Great American University: Its Rise to Preeminence, Its Indispensable National Role, Why It Must be Protected. N.Y.: PublicAffairs, 2010.616 p.

33. Bell D. The Axial Age of Technology Foreword: 1999 // Bell D. The Coming of Post-Industrial Society: A Venture of Social Forecasting. N.Y.: Basic Books, 2008. P. ix-lxxxvi.

34. The Role of the Universities in the Europe of Knowledge / Communication from the Commission. Brussels: Commission of the European Communities, 2003. 23 p.

35. Delivering on the Modernisation Agenda for Universities: Education, Research and Innovation / Communication from the Commission to the Counsil and the European Parlament. Brussels: Commission of the European Communities, 2006.16 p. 
36. Karpov A.O. Sotsiokognitivnaya struktura i obrazovanie v obshchestve znanii // Obshchestvo i ekonomika. 2013. №11-12. S. 5-20.

37. Karpov A.O. Knowledge Society: A Weak Link // Herald of the Russian Academy of Sciences. N.Y.: Pleiades Publishing, 2010. Vol. 80. №4. P. 373-376.

38. Creativity in Higher Education: Report on the EUA Creative Project - 2007. Brussels: European University Association, 2007. 44 p.

39. Creative Economy Report 2008. N.Y.: United Nations, 2008. 332 p.

40. Peters A., Besley T. Introduction: The Creative University // The Creative University / ed. by A. Peters, T. Besley. Rotterdam: Sense Publishers, 2013. 190 p.

41. Hammershoj L.G. Creativity as a Question of Bildung // Journal of Philosophy of Education. Oxford: Blackwell Publishing, 2009. Vol. 43. №4. P. 545-557.

42. Karpov A.O. Kommodifikatsiya obrazovaniya v rakurse ego tselei, ontologii i logiki kul'turnogo dvizheniya // Voprosy filosofii. 2012. №10. S. 85-96.

43. Drucker P.F. Post-Capitalist Society. New York City: Harper Business, 1993. 232 p.

44. Deem R., Hillyard S., Reed M. Knowledge, Higher Education, and the New Managerialism: The Changing Management of UK Universities. N.Y.: Oxford University Press, 2010. P. 6.

45. Karpov A.O. Ontologizatsiya, "ontologizatsiya" i obrazovanie // Voprosy filosofii. 2013. №9. S. 34-36.

46. Pruzhinin B.I. Ratio serviens? Kontury kul'turno-istoricheskoi epistemologii. M.: ROSSPEN, 2009. $423 \mathrm{~s}$.

47. Bechmann G., Gorokhov V., Stehr N. Introduction // The Social Integration of Science: Institutional and Epistemological Aspects of the Transformation of Knowledge in Modern Society. Berlin: Editional Sigma, 2009. $312 \mathrm{p}$. 